\title{
The role of exosomes in tumor progression and metastasis (Review)
}

\author{
WIKTORIA M. SUCHORSKA ${ }^{1,3}$ and MICHAL S. LACH ${ }^{1,2}$ \\ ${ }^{1}$ Radiobiology Laboratory, Greater Poland Cancer Centre, 61-866 Poznan; \\ ${ }^{2}$ Postgraduate School of Molecular Medicine, Warsaw University of Medical Sciences, 02-091 Warsaw; \\ Department of Electroradiology, Poznan University of Medical Sciences, 61-866 Poznan, Poland
}

Received October 12, 2015; Accepted November 12, 2015

DOI: $10.3892 /$ or.2015.4507

\begin{abstract}
Tumor cells have developed various mechanisms in defense against applied treatment, which prevent their total elimination from an organism. One of the underestimated mechanisms of defense is secretion of highly specialized doublemembrane structures called exosomes. They play a crucial role in the control of the local microenvironment and intracellular communication. It has been shown that the exosomes can be carriers of various proteins, lipids, miRNAs and mRNAs. There are extensive data concerning the influence and participation by exosomes in metastasis and cancer progression. It has been demonstrated that exosomes are involved in multidrug resistance mechanisms, radiation-induced bystander effect and epithelialmesenchymal transition. Furthermore, exosomes are able to form a premetastatic niche and enable the escape of cancer cells from recognition by host immune cells. Moreover, exosomes are responsible for the formation of vessels. This indicates the significance of secreted extracellular vesicles in the development and prognosis of cancer. The aim of the present review is to briefly describe the role of exosomes in tumor biology.
\end{abstract}

\section{Contents}

1. Introduction

2. The types and biogenesis of different extracellular vesicles

3. Role of exosomes in radiotherapy resistance

4. Exosomes as another mediator of the radiation-induced bystander effect

5. The role of exosomes in drug resistance

6. Exosomes promote the invasion and spreading of tumors

7. Tumor immune escape

8. Conclusions

Correspondence to: Michal S. Lach, Radiobiology Laboratory, Greater Poland Cancer Centre, 15 Garbary Street, 61-866 Poznan, Poland

E-mail: michal.lach@wco.pl; lach.michal89@gmail.com

Key words: immune escape, multidrug resistance, radioresistance, radiation-induced bystander effect, extracellular vesicles, epithelialmesenchymal transition

\section{Introduction}

The tumor microenvironment plays a crucial role in the control of the host immune response, cancer development and the formation of distal metastases. One of the mechanism that could explain the ability of cancer cells to resist the toxic effects of drugs and radiotherapy is through the release of highly specialized and functional bilayer membrane structures called exosomes. Recently, the different types of extracellular vesicles have been intensively investigated according to their cargo, which could be used as a source of information concerning prognosis, patient condition and the effectiveness of applied treatment.

Exosomes were initially described by Trams $e t$ al in the 1980s. Exoxomes were found to indicate the presence of extracellular vesicles containing active 5'-ectonucleotidase released from different types of normal and cancer cell lines (1). In 1987, Johnstone et al demonstrated the appearance of multifunctional vesicles, which are involved in reticulocyte maturation (2). Exosomes can be obtained from various body fluids such as amniotic fluid, ascites, nasal lavage fluid, saliva, serum, plasma, breast milk, urine, cerebrospinal fluid, as well as from cell culture medium (3-5). At first, it was thought that exosomes were secreted by cells as a waste cargo. However, the development of molecular techniques has brought new insights into their function as a crucial factor in cell-cell communication and in the regulation of the tissue microenvironment (6-8). The complexity of their structure has been confirmed by many studies, which has led to development of a database (http://microvesicles.org; http:// exocarta.org) describing the content of the vesicle cargo. It has been detected that this extracellular vesicle can be a carrier of as many as 92,897 proteins, 584 lipids, 4,934 miRNAs and 27,642 mRNAs.

The amount of detected exosomes in patients diagnosed with cancer and autoimmune diseases was found to be increased compared to healthy controls. This confirms the significant role of exosomes in the development and progression of various types of diseases. However, the mechanisms and the recognition of specific exosomal cargo content involved in the progression of disease are still a challenge for researchers. Many data suggest that according to different physical (ionizing radiation, heat) or chemical factors (low 

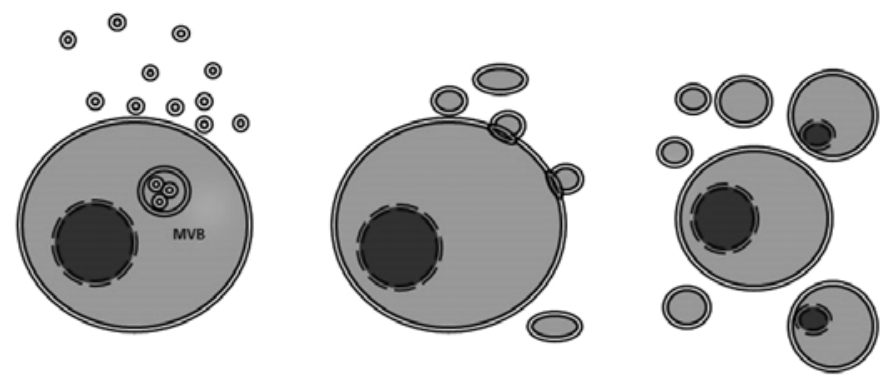

\begin{tabular}{|c|c|c|c|}
\hline & Exosomes & Microvesicles & Apoptotic bodies \\
\hline $\begin{array}{c}\text { Size of } \\
\text { vesicles / } \\
\text { Shape }\end{array}$ & 30-100 nm, regular & 100-1000 nm, irregular & 50-5000 nm, irregular \\
\hline Markers & $\begin{array}{c}\text { LAMP-1, tetraspanins, } \\
\text { Alix, MHC -1, -1I, HSP70, } \\
\text { TSG100 }\end{array}$ & $\begin{array}{c}\text { Selectins, integrins, tissues } \\
\text { factor and cell-specific } \\
\text { markers }\end{array}$ & Histones, organelles \\
\hline Origin & $\begin{array}{c}\text { Endosomal } \\
\text { compartments of cells }\end{array}$ & $\begin{array}{c}\text { Cell surface plasma } \\
\text { membrane }\end{array}$ & $\begin{array}{c}\text { Cells which undergo } \\
\text { apoptosis }\end{array}$ \\
\hline
\end{tabular}

Figure 1. General characterization of the extracellular vesicle population based on size and origin. MVB, multivesicular body.

$\mathrm{pH}$ level, increased concentration of calcium, oxidative stress, hypoxia), the content and amount of vesicles secreted by the same cell lines can be totally different. This suggests how cells communicate and how they accommodate to unfavorable conditions via exosome release (9-12).

\section{The types and biogenesis of different extracellular vesicles}

The three main types of double membrane structures can be distinguished: apoptotic bodies, microvesicles (ectosomes) and exosomes. They have various pathways of formation and protein content (Fig. 1). During programmed cell death, the cell divides itself into small membrane irregular-shaped apoptotic bodies. They are carriers of degraded nuclei, DNA fragments, histones and other organelles. The size of apoptotic bodies is heterogeneous (from $50 \mathrm{~nm}$ to $5 \mu \mathrm{m}$ ), resulting in various sedimentation of these structures (1,200-100,000 x g) (13). Ectosomes are a membranous vesicle population from the cell surface membrane. The ectosome size is in the range $100-1,000 \mathrm{~nm}$, which allows their isolation by centrifugation with a speed of 10,000-100,000 x g. They have a similar content of cell surface proteins as cells derived from ectosomes. The third population of vesicles are cup-shaped, double membrane structures called exosomes. Exosomes are isolated mostly by ultracentrifugation $(\geq 100,000 \mathrm{x} \mathrm{g})$. Exosomes are secreted from intracellular compartments (Fig. 2). Early endosomes are formed via non-clathrin or clathrin-mediated endocytosis. After formation of late endosomes by acidification of early endosomes, the multivesicular bodies (MVBs) are formed by the invagination of endosomal membranes. Inside an MVB, intraluminal vesicles (ILVs) are present (14). They have various cargo contents, such as ribonucleic acids (miRNAs, mRNAs), proteins (receptors, enzymes, immunomodulatory molecules, proangiogenic factors, apoptosis ligands, endosomal origin proteins, signaling molecules, tetraspanins), lipids (ceramide, cholesterol, sphingomyelin) and viral particles (15-17). MVBs filled with ILVs can undergo lysosomal degradation or can be led to fuse with the surface plasma membrane, where ILVs are released as exosomes. Secretion and the composition of exosomes are dependent on a protein complex called endosomal sorting complexes required for transport (ESCRT), composed of five distinct molecules, which are involved in stabilization of the size and cargo of ILVs (18). The fusion of the MVB with the plasma membrane is the final step before secretion of exosomes into the extracellular environment. It has been suggested that the fusion of exosomes with the plasma membrane requires soluble $\mathrm{N}$-ethylmaleimide-sensitive factor attachment protein receptors (SNAREs), which form the anchor-complex between the vesicular and plasma membrane SNAREs $(19,20)$. Furthermore, vesicles are secreted by taking advantage of small GTPases Rab11, Rab22, Rab27, proteins which are involved in vesicular transport (21-23).

Besides the physiological function of exosomes, such as cellular communication and transfer of signals i.e. neuron communication, exosomes can be used by cancer cells to manipulate the local environment $(24,25)$. Many data suggest that increased secretion of functional cancer exosomes into the extracellular environment is involved in the progression and formation of metastases (Fig. 3) (26-29). Some of the mechanisms connected with treatment failure, progression of the disease, and an explanation of those via exosome secretion will be further described in this review.

\section{The role of exosomes in radiotherapy resistance}

The radioresistance of cancer cells is acquired by hypoxia, genetic heterogeneity of cancer cells (TP53 mutants) or an efficient mechanism of DNA repair $(30,31)$. Tumor irradiation results in the secretion of exosomes, which are messengers for surrounding cells. Data have revealed changes in the cargo of exosomes, which plays a pivotal role in cancer survival. One of the studies suggested that radiotherapy can induce the increased viability of cancer cells by releasing exosomes containing survivin, which is a member of the IPA gene family involved in inhibition of the apoptosis signaling pathway. 


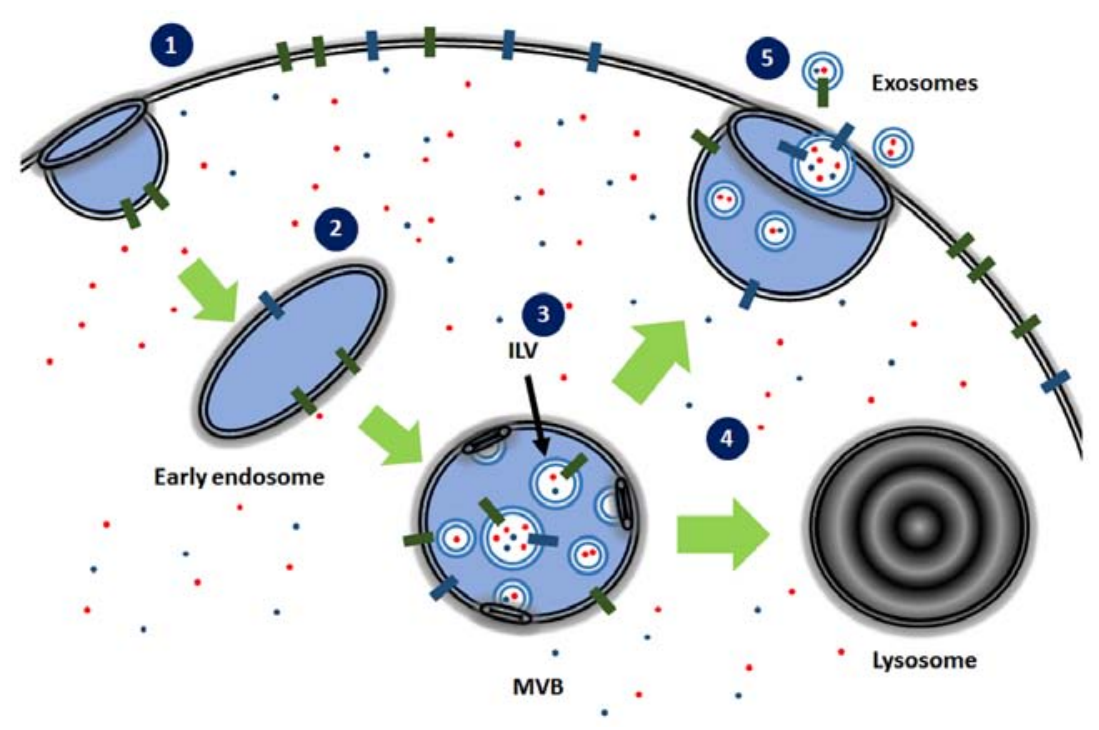

Figure 2. The biogenesis of exosomes. Early endosomes (2) are formed from the cell plasma membrane (1) via non-clathrin or clathrin-mediated endocytosis. Multivesicular bodies (MVBs) are formed by the invagination of endosomal membranes. Inside an MBV, intraluminal vesicles (ILVs) (3) are present which have various cargo content (tetraspanins, ESCRT protein complex, ceramides). Dependent on the function and cargo content, MVBs can be directed to fuse with lysosomes (4) to degrade all cargo or to fuse with the plasma cell membrane to release the ILVs as exosomes (5).

\section{RIBE}

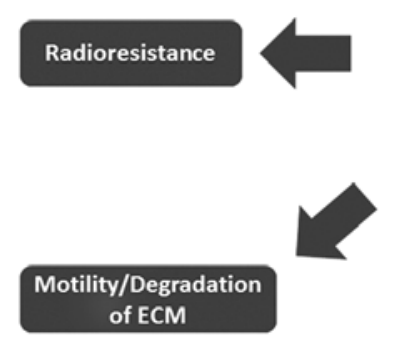

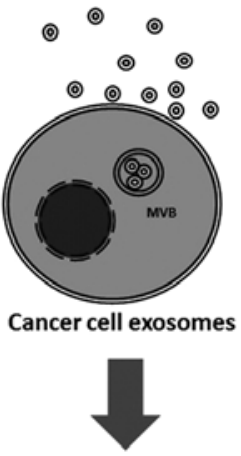

Neovascularization
Chemoresistance
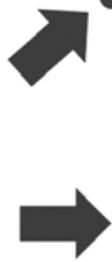

EMT

Figure 3. The role of tumor-derived exosomes in the progression of cancer. RIBE, radiation-induced bystander effect; EMT, epithelial-mesenchymal transition; ECM, extracellular matrix.

This may enhance the cancer cell survival fraction, which is connected with a poorer outcome for patients. Moreover, the secretion of exosomes was not increased, while the concentration of survivin was higher in HeLa irradiated cells (3 Gy) in comparison with non-irradiated cells (32).

It was demonstrated that exosomes participated in cancer progression after X-ray irradiation of various glioblastoma cell lines. After irradiation with a 4-Gy dose of irradiation, the exosome secretion increased in a dose-dependent manner. However, after irradiation, the released exosomes were more chemoattractant for tumor cells and were better taken up by recipient cell human endothelial umbilical cord vein cells (HUVECs). The migration and invasive markers such as connective tissue growth factor (CTGF) and insulin-like growth factor binding protein 2 (IGFBP2) mRNA levels were increased in exosomes isolated from irradiated cells in comparison with exosomes derived from non-irradiated cells (11).

\section{Exosomes as another mediator of the radiation-induced bystander effect}

It has been observed that radiation of tumors can cause damage to healthy cells, even when they are not exposed. This effect is called radiation-induced bystander effect (RIBE). RIBE causes DNA damage, genomic instability (GI), cell death and micronucleation of healthy cells (33). Two methods for delivering information from irradiated cells to radiated cells have been observed. These were through cell gap junctions or soluble factors [reactive oxygen species (ROS) and reactive nitrogen species; interleukin (IL)-6 and -8; tumor necrosis factor- $\alpha$ (TNF- $\alpha$ ); transforming growth factor 1 (TGF- $\beta 1)]$ (33-35). 
Exosomes, as a carrier of RNA, can deliver messages to distal and surrounding cells (36). In irradiated cells, it was observed that RNA molecules delivered by exosomes induced GI and RIBE. This was demonstrated on exosomes derived from the medium of an irradiated breast cancer cell line (MCF-7). After irradiation of cells with 2 Gy of X-rays, the medium was collected and incubated with non-irradiated cells. Comet degradation tail assay indicated the presence of increased DNA damage in the early and late passages of cells co-incubated with irradiated conditioned medium exosomes in comparison with exosomes isolated from the non-irradiated cells. To confirm the participation of exosomal RNA in GI, exosomes isolated from medium of irradiated and non-irradiated were treated with RNase. No changes were noted in early effects, but late effects of GI were observed. There was no explicit conclusion concerning the type of RNA (miRNA or RNA) involved in these changes (37). The authors suggested miRNA participation, due to its ability to cause epigenetic changes or additional influence of unknown proteins carried by those vesicles (38).

Another study by Jella et al demonstrated the correlation between exosomes secreted via irradiated cells, as a mediator of RIBE in a human keratinocyte cell line. Media from irradiated ( $\gamma$-ray doses, $0.005,0.05$ and $0.5 \mathrm{~Gy}$ ) HaCaT cells were used. It was revealed that exosomes isolated from the medium of irradiated cells were involved in the production of ROS and decreased viability of non-irradiated cells. Additionally, increased influx of calcium was induced by exosomes derived from irradiated cells, which is a typical signal of irradiation exposure or mechanical stress $(39,40)$.

\section{Role of exosomes in drug resistance}

Multidrug resistance (MDR) in cancer cells is caused by various mechanisms which allows them to resist cytostatic and cytotoxic effects of applied drugs. It is mostly caused by membrane protein ATP-binding cassettes (ABCs), which enable the exclusion of cytotoxic substances from the intracellular environment $(41,42)$. Another cause of MDR is through the variable activity of cytochrome P450, which is caused by various genetic variants of the CYP gene family. They are related to a more efficient metabolism of drugs by cancer cells, resulting in a decreased cytotoxic effect of applied drugs (43). Furthermore, many tumors have developed efficient systems for DNA-damage repair, where DNA is a target of most anticancer drugs $(31,44,45)$.

Data suggest that exosomes play a pivotal role in the lack of response to cytostatic treatment. This hypothesis was confirmed by investigation of the influence of cisplatin on a resistant ovarian cancer cell line. It was demonstrated that an increased release of exosomes was associated with drug administration. Moreover, the drugs were effluxed in vesicle cargo. The increased expression of genes involved in cellular transport such as copper-transporting ATPase 1 (ATP7A), ATPase, $\mathrm{Cu}^{++}$transporting, $\beta$ polypeptide (ATP7B), MDR-associated protein 2 (MRP2) was observed after cisplatin treatment of ovarian cancer (46).

Breast cancer cell lines with overexpression of HER2 (SKBR3, BT474) and HER1 (MDA-MB-231) were found to display resistance to applied trastuzumab and lapatinib (tyrosine kinase inhibitor). The decrease in effectiveness was caused by release of HER2-positive exosomes. Furthermore, hepatocyte growth factor (HGF) and epidermal growth factor (EGF) induced increased secretion of exosomes into the extracellular space. Drug attachment to tumor cell surface receptors was found to be decreased due to the binding to receptors expressed on the vesicle surface, which caused the limited effectiveness of therapy. However, co-incubation of cells with HER2-exosomes increased the proliferation of cells. Moreover, the analysis of serum-derived exosomes from a group of patients with early and advanced HER-positive breast cancer indicated a higher affinity to trastuzumab of exosomes obtained from advanced breast cancer patients (47).

Xiao et al demonstrated the role of exosomes in cisplatin resistance of lung cancer cell line A549 and showed the potential role of exosomes as carriers of information in response to cytotoxic stress. Cisplatin caused increased secretion of exosomes in comparison with non-treated cells. Cells co-incubated with exosomes derived from cisplatintreated cells demonstrated higher proliferation and increased viability in comparison with cells treated with cisplatin alone. Additionally, the expression of genes involved in DNA repair and miRNAs related to drug resistance are increased, which enable cells to decrease their sensitivity to a second response of applied cisplatin (48).

Tumors are formed from distinct cell populations. This heterogeneity of tumor structure leads to the occurrence of sensitivity and resistance to applied treatment. It is related to the genetic variability of cancer cells. Chen et al demonstrated the ability of breast cancer MCF-7 cells to transfer the resistance to therapeutic drugs between their own cell population (MCF-7 cells resistant to adriamycin, docetaxel) and MCF-7 cells sensitive to those drugs via exosomes. The apoptosis of sensitive cells was decreased after treatment of the drugs. This was achieved prior to co-incubation of cells sensitive to drugs with exosomes derived from drug-resistant cells. Authors, by profiling exosomal RNAs, have identified potential miRNAs which could be involved in the horizontal transfer of chemoresistance via exosomes (miR-100, miR-222, miR-30a and miR-17) (49).

\section{Exosomes promote the invasion and spreading of tumors}

In addition to the influence of external factors which trigger increased secretion of exosomes by cancer cells, several studies have demonstrated the participation of extracellular vesicles in the expansion of tumor cells in the host organism. The mechanism which is responsible for this outcome is epithelial-mesenchymal transition (EMT). During EMT, cells are altered at the molecular level and in regards to cell morphology, which causes the increased potential for migration. The E-cadherin level decreases, whereas levels of $\mathrm{N}$-cadherin and vimentin increase. Moreover, it has been observed that production of extracellular matrix (ECM) components, such as collagens and fibronectin, was also increased. Cell shape is altered from a regular to a more spindle-like shape, which results in the weakening of gap junction connections and increased motility (50-53). EMT can be induced by an interplay of various signaling pathways mainly by participation of TGF- $\beta 1$, Wnt proteins, EGF, HGF 
and MMPs (54-58). Moreover, the presence of these proteins was confirmed in exosomal cargos, suggesting that EMT mechanisms can be controlled by cancer-derived exosomes. The TGF- $\beta$ protein family carries out various significant functions in organisms. Generally, during the healing process, exosomes containing TGF- $\beta 1$ mRNA or TGF- $\beta 1$ protein are responsible for the formation of fibrosis in the epithelium by increased production of ECM components (59). In tumors, it was observed that exosomes derived from cancer cells are enriched in TGF- $\beta 1$ causing differentiation of fibroblasts into myofibroblasts. Increased expression of $\alpha$-smooth muscle actin was noted after exposure of exosomes derived from various cancer cell lines (58). Furthermore, it was found that cancerassociated fibroblasts (CAFs) by exosome secretion are able to induce the Wnt-PCP signaling pathway in breast cancer cells, resulting in increased motility and invasiveness of cancer cells (60). Additionally, the Wnt signaling pathway is significant in exosome secretion via a $\mathrm{Ca}^{2+}$-dependent mechanism, which was indicated after exposure to recombinant WNT5A of melanoma cells. WNT5A secretion is correlated with poor prognosis and advanced stage of disease in melanoma cancer patients (61). The presence of WNT5A is highly correlated with increased secretion of exosomes containing IL-6, IL-8, VEGF and MMP2. This promotes immunomodulatory and proangiogenic properties of the tumor microenvironment, enabling them to progress and form distal metastases (62).

The mechanism involved in cancer cell motility and tumor invasive features was explained by activation of MMP2 by release of HSP90 $\alpha$ via exosomes. In a breast cancer cell line, released exosomes containing HSP90 $\alpha$ induced increased regeneration of the wound in a wound healing assay. Furthermore, cancer cells after co-incubation with exosomes demonstrated a less rounded shape and increased motility. Similar results were obtained by addition of recombinant HSP90 $\alpha$, which can explain its role in the induction of metastasis and motility of cancer cells via secreted exosomes (63). The motility of cancer cells was possible by activation of MMPs through release into the environment of HSP90, which was shown in MCF-7 GFP cells by increased ability to penetrate collagen blocks (64).

The significant role of exosomes in the rapid spreading of cancer cells was also displayed by their participation in the process of the formation of vessels. This mechanism is highly correlated with the presence of hypoxic areas in therapy-resistant tumors. Increased potential to form neovessels was observed in exosomes derived from glioblastoma patients and cell lines. The exosome protein analysis indicated increased levels of transcripts and proteins including IL-8, VEGF, which are crucial for vessel formation. Hence, it was demonstrated that a hypoxic condition increased the ability of cancer cells to migrate by upregulation of proteins such as IGFB1 and IGFB3 in exosomes. Moreover, increased levels of IL-8, caveolin 1 (CAV1), MMP9 and PDGF in exosomes can be potentially used as an exosomal marker of hypoxia in glioblastoma cancer patients, which is crucial for the effectiveness of therapy $(10,65)$. The promotion of angiogenesis and the formation of lung metastasis were indicated by exosomes obtained from $\mathrm{CD} 15^{+}$renal cancer stem cells. These exosomes displayed a higher potential for formation of vessels in vitro. An increased number of lung metastases were observed in
SCID mice pre-treated with $\mathrm{CD} 105^{+}$exosomes before injection of renal cancer cells in comparison with pre-treatment of mice with exosomes obtained from $\mathrm{CD}^{\circ} 5^{-}$renal cancer cells. This demonstrates the significance of the cancer stem cell population and the role of exosomes in the invasive behavior and resistance of tumors (66).

\section{Tumor immune escape}

The enhanced proliferation of cancer cells and their instability can cause the development of different types of antigens $(67,68)$. Under a physiological condition, immune innate cells are responsible for the elimination of pathologically altered cells, which may potentially undergo malignant transformation. However, various cancer cells have developed various mechanisms, which enable them to avoid the immune response. These processes include low expression of major histocompatibility complex I (MHC I) and MHC II, mutation or downregulation of tumor-associated antigens and lack of adhesive molecules, which generate the tolerance of the immune system. Another important pathway that causes impairment of the response from host immune cells to the presence of cancer cells is production of soluble factors acting as immunosuppressive molecules i.e. VEGF, IL-10, TGF $\beta 1$ and adenosine (69-72).

One of the mechanism leading to control of the immune cells by cancer cells is production of immunosuppressive adenosine in the presence of CD39 and CD73 on cancer exosomes and on the surface of cancer cells. The degradation of ATP to immunosuppressive adenosine via ectonucleotides by T-regulatory (Treg) cells is one of the mechanism that attenuates the response from T-effector (Teff) cells. However, the activity of Teff cells is decreased by elevated intracellular level of cAMP, which is the consequence of the binding of immunosuppressive adenosine to the adenosine A2a receptor $(71,73)$. Tumor cells also taken advantage of the adenosinergic pathway to increase their survival fraction. It was shown that breast, colorectal, bladder, melanoma, mesothelioma and prostate cancer cell lines exhibit CD39 and CD73 on the surface of exosomes, which are enzymatically active and able to influence the functionality of T-cells by production of immunosuppressive adenosine (74).

TGF- $\beta 1$ has various functions that include induction of the differentiation of fibroblasts to myofibroblasts and regulation of the expression of ECM components $(58,75)$. However, one important role of this protein is its inhibitory property of silencing immune cell response particularly for NK cells. Exosomes isolated from acute myeloid leukemia silenced the response of NK cells via downregulation of NKG2D receptor expression, caused by the presence of TGF- $\beta 1$ and MICA/ MICB in the exosomal cargo $(76,77)$. In contrast, the presence of TGF- $\beta 1$ and IL-10 in the microenvironment promoted the proliferation of Treg cells and changed the Teff phenotype from $\mathrm{CD} 4{ }^{+} \mathrm{CD} 25^{-}$to Treg cells $\left(\mathrm{CD} 4{ }^{+} \mathrm{CD} 25^{+} \mathrm{FOXP} 3^{+}\right)$by activation of the Foxp3 transcript factor (78). The increased frequency of Treg cells in the blood of cancer patients indicate their significant role in the prevention of tumor cells by their suppressive properties $(78,79)$.

Another pathway involved in the regulation of immune cells in the tumor microenvironment and the silencing of their 
response towards primary cancer cells is secretion of vesicles expressing FasL molecule on their surface. After binding of the Fas ligand with the Fas receptor on activated immune cells, the cells trigger reprogrammed cell death (80). Serum of oral squamous cell carcinoma (SCC) and head and neck SCC patients were enriched in $\mathrm{FasL}^{+}$exosomes, which caused the decreased functioning of $\mathrm{CD}^{+}$Jurkat cells. Additionally, the presence of a high concentration of FasL in exosomes and serum were correlated with poorer prognosis of cancer patients $(81,82)$. However, this mechanism is also significant under physiological conditions. The release of FasL and TRAIL-positive exosomes by trophoblast cells was able to silence maternal activated immune cells directed to the fetus (80).

\section{Conclusions}

The role of the tumor microenvironment and its interaction via released exosomes is an appropriate model to describe and explain many of the unknown mechanisms involved in the progression and formation of metastases in cancer patients. Recently, the role of exosomes in the progression and metastasis of cancer cells has been widely reported and intensively explored. Unique exosomal cargo contents can be used in the future as potential predictive biomarkers, which enable the observation of patients before and during treatment. However, their full cargo is still not well known and the implications in regards to the control of the local and systemic environment of the host organism are not defined. However, the specific separation of only one extracellular membrane vesicle subpopulation is problematic due to the wide size range, and characterization of their content remains a challenge for researchers.

\section{Acknowledgements}

The present review was funded by the National Science Centre allocated on the basis of decision no. 2012/07/E/NZ3/01819.

\section{References}

1. Trams EG, Lauter CJ, Salem N Jr and Heine U: Exfoliation of membrane ecto-enzymes in the form of micro-vesicles. Biochim Biophys Acta 645: 63-70, 1981.

2. Johnstone RM, Adam M, Hammond JR, Orr L and Turbide C: Vesicle formation during reticulocyte maturation. Association of plasma membrane activities with released vesicles (exosomes). J Biol Chem 262: 9412-9420, 1987.

3. Oosthuyzen W, Sime NEL, Ivy JR, Turtle EJ, Street JM, Pound J, Bath LE, Webb DJ, Gregory CD, Bailey MA, et al: Quantification of human urinary exosomes by nanoparticle tracking analysis. J Physiol 591: 5833-5842, 2013.

4. Street JM, Barran PE, Mackay CL, Weidt S, Balmforth C, Walsh TS, Chalmers RT, Webb DJ and Dear JW: Identification and proteomic profiling of exosomes in human cerebrospinal fluid. J Transl Med 10: 5, 2012.

5. Lässer C, Alikhani VS, Ekström K, Eldh M, Paredes PT, Bossios A, Sjöstrand M, Gabrielsson S, Lötvall J and Valadi H: Human saliva, plasma and breast milk exosomes contain RNA Uptake by macrophages. J Transl Med 9: 9, 2011.

6. Théry C: Exosomes: Secreted vesicles and intercellular communications. F1000 Biol Rep 3: 15, 2011.

7. Umezu T, Ohyashiki K, Kuroda M and Ohyashiki JH: Leukemia cell to endothelial cell communication via exosomal miRNAs. Oncogene 32: 2747-2755, 2013.

8. Vlassov AV, Magdaleno S, Setterquist R and Conrad R: Exosomes: Current knowledge of their composition, biological functions, and diagnostic and therapeutic potentials. Biochim Biophys Acta 1820: 940-948, 2012.
9. de Jong OG, Verhaar MC, Chen Y, Vader P, Gremmels H, Posthuma G, Schiffelers RM, Gucek M and van Balkom BW: Cellular stress conditions are reflected in the protein and RNA content of endothelial cell-derived exosomes. J Extracell Vesicles 1: 18396, 2012.

10. Kucharzewska P, Christianson HC, Welch JE, Svensson KJ, Fredlund E, Ringnér M, Mörgelin M, Bourseau-Guilmain E, Bengzon J and Belting M: Exosomes reflect the hypoxic status of glioma cells and mediate hypoxia-dependent activation of vascular cells during tumor development. Proc Natl Acad Sci USA 110: 7312-7317, 2013.

11. Arscott WT, Tandle AT, Zhao S, Shabason JE, Gordon IK, Schlaff CD, Zhang G, Tofilon PJ and Camphausen KA: Ionizing radiation and glioblastoma exosomes: Implications in tumor biology and cell migration. Transl Oncol 6: 638-648, 2013.

12. Maheshwari S, Singh AK, Arya RK, Pandey D, Singh A and Datta D: Exosomes: Emerging players of intercellular communication in tumor microenvironment. Disoveries 2: e26, 2014.

13. van Dommelen SM, Vader P, Lakhal S, Kooijmans SA, van Solinge WW, Wood MJ and Schiffelers RM: Microvesicles and exosomes: Opportunities for cell-derived membrane vesicles in drug delivery. J Control Release 161: 635-644, 2012.

14. Taylor DD and Gercel-Taylor C: The origin, function, and diagnostic potential of RNA within extracellular vesicles present in human biological fluids. Front Genet 4: 142, 2013.

15. Kharaziha P,Ceder S, Li Q and Panaretakis T: Tumor cell-derived exosomes: A message in a bottle. Biochim Biophys Acta 1826: 103-111, 2012.

16. Escrevente C, Grammel N, Kandzia S, Zeiser J, Tranfield EM, Conradt HS and Costa J: Sialoglycoproteins and N-glycans from secreted exosomes of ovarian carcinoma cells. PLoS One 8: e78631, 2013.

17. Rappa G, Mercapide J, Anzanello F, Pope RM and Lorico A: Biochemical and biological characterization of exosomes containing prominin-1/CD133. Mol Cancer 12: 62, 2013.

18. van den Boorn JG, Dassler J, Coch C, Schlee M and Hartmann G: Exosomes as nucleic acid nanocarriers. Adv Drug Deliv Rev 65: 331-335, 2013.

19. Gross JC, Chaudhary V, Bartscherer K and Boutros M: Active Wnt proteins are secreted on exosomes. Nat Cell Biol 14: 1036-1045, 2012

20. Urbanelli L, Magini A, Buratta S, Brozzi A, Sagini K, Polchi A, Tancini B and Emiliani C: Signaling pathways in exosome biogenesis, secretion and fate. Genes 4: 152-170, 2013.

21. Bobrie A, Krumeich S, Reyal F, Recchi C, Moita LF, Seabra MC, Ostrowski $\mathrm{M}$ and Théry C: Rab27a supports exosome-dependent and -independent mechanisms that modify the tumor microenvironment and can promote tumor progression. Cancer Res 72: 4920-4930, 2012.

22. Raposo G and Stoorvogel W: Extracellular vesicles: Exosomes, microvesicles, and friends. J Cell Biol 200: 373-383, 2013.

23. Frydrychowicz M, Kolecka-Bednarczyk A, Madejczyk M, Yasar S and Dworacki G: Exosomes - structure, biogenesis and biological role in non-small-cell lung cancer. Scand $\mathbf{J}$ Immunol 81: 2-10, 2015.

24. Lachenal G, Pernet-Gallay K, Chivet M, Hemming FJ, Belly A, Bodon G, Blot B, Haase G, Goldberg Y and Sadoul R: Release of exosomes from differentiated neurons and its regulation by synaptic glutamatergic activity. Mol Cell Neurosci 46: 409-418, 2011.

25. Stoorvogel W, Kleijmeer MJ, Geuze HJ and Raposo G: The biogenesis and functions of exosomes. Traffic 3: 321-330, 2002.

26. Friel AM, Corcoran C, Crown J and O Driscoll L: Relevance of circulating tumor cells, extracellular nucleic acids, and exosomes in breast cancer. Breast Cancer Res Treat 123: 613-625, 2010.

27. Vaksman O, Tropé C, Davidson B and Reich R: Exosome-derived miRNAs and ovarian carcinoma progression. Carcinogenesis 35 : 2113-2120, 2014.

28. Zhang HG and Grizzle WE: Exosomes: A novel pathway of local and distant intercellular communication that facilitates the growth and metastasis of neoplastic lesions. Am J Pathol 184: 28-41, 2014.

29. Nikitina IG, Sabirova EIu, Karpov VL, Lisitsyn NA and Beresten' SF: The role of exosomes and microvesicles in carcinogenesis. Mol Biol 47: 767-773, 2013 (In Russian).

30. Martin BJ: Inhibiting vasculogenesis after radiation: A new paradigm to improve local control by radiotherapy. Semin Radiat Oncol 23: 281-287, 2013.

31. Roos WP and Kaina B: DNA damage-induced cell death: From specific DNA lesions to the DNA damage response and apoptosis. Cancer Lett 332: 237-248, 2013. 
32. Khan S, Jutzy JMS, Aspe JR, McGregor DW, Neidigh JW and Wall NR: Survivin is released from cancer cells via exosomes. Apoptosis 16: 1-12, 2011.

33. Jalal N, Haq S, Anwar N, Nazeer S and Saeed U: Radiation induced bystander effect and DNA damage. J Cancer Res Ther 10: 819-833, 2014.

34. Sokolov MV and Neumann RD: Radiation-induced bystander effects in cultured human stem cells. PLoS One 5: e14195, 2010.

35. Mothersill C and Seymour CB: Radiation-induced bystander effects - implications for cancer. Nat Rev Cancer 4: 158-164, 2004.

36. Cheng L, Sharples RA, Scicluna BJ and Hill AF: Exosomes provide a protective and enriched source of miRNA for biomarker profiling compared to intracellular and cell-free blood. J Extracell Vesicles 3: 3, 2014.

37. Al-Mayah AHJ, Irons SL, Pink RC, Carter DRF and Kadhim MA Possible role of exosomes containing RNA in mediating nontargeted effect of ionizing radiation. Radiat Res 177: 539-545, 2012

38. Hummel R, Hussey DJ and Haier J: MicroRNAs: Predictors and modifiers of chemo- and radiotherapy in different tumour types. Eur J Cancer 46: 298-311, 2010.

39. Jella KK, Rani S, O Driscoll L, McClean B, Byrne HJ and Lyng FM: Exosomes are involved in mediating radiation induced bystander signaling in human keratinocyte cells. Radiat Res 181 138-145, 2014

40. Savina A, Furlán M, Vidal M and Colombo MI: Exosome release is regulated by a calcium-dependent mechanism in K562 cells. J Biol Chem 278: 20083-20090, 2003.

41. Rubiś B, Hołysz H, Barczak W, Gryczka R, Łaciński M, Jagielski P, Czernikiewicz A, Półrolniczak A, Wojewoda A, Perz K, et al: Study of $A B C B 1$ polymorphism frequency in breas cancer patients from Poland. Pharmacol Rep 64: 1560-1566, 2012.

42. Eckford PDW and Sharom FJ: ABC efflux pump-based resistance to chemotherapy drugs. Chem Rev 109: 2989-3011, 2009.

43. Rodriguez-Antona $C$ and Ingelman-Sundberg M: Cytochrome $P 450$ pharmacogenetics and cancer. Oncogene 25: 1679-1691, 2006.

44. Rebucci M and Michiels C: Molecular aspects of cancer cell resistance to chemotherapy. Biochem Pharmacol 85: 1219-1226, 2013.

45. Luciani F, Spada M, De Milito A, Molinari A, Rivoltini L, Montinaro A, Marra M, Lugini L, Logozzi M, Lozupone F, et al: Effect of proton pump inhibitor pretreatment on resistance of solid tumors to cytotoxic drugs. J Natl Cancer Inst 96: 1702-1713, 2004.

46. Safaei R, Larson BJ, Cheng TC, Gibson MA, Otani S, Naerdemann W and Howell SB: Abnormal lysosomal trafficking and enhanced exosomal export of cisplatin in drug-resistant human ovarian carcinoma cells. Mol Cancer Ther 4: 1595-1604, 2005.

47. Ciravolo V, Huber V, Ghedini GC, Venturelli E, Bianchi F, Campiglio M, Morelli D, Villa A, Della Mina P, Menard S, et al: Potential role of HER2-overexpressing exosomes in countering trastuzumab-based therapy. J Cell Physiol 227: 658-667, 2012.

48. Xiao X, Yu S, Li S, Wu J, Ma R, Cao H, Zhu Y and Feng J: Exosomes: Decreased sensitivity of lung cancer A549 cells to cisplatin. PLoS One 9: e89534, 2014.

49. Chen WX, Liu XM, Lv MM, Chen L, Zhao JH, Zhong SL, Ji MH, $\mathrm{Hu} \mathrm{Q}$, Luo Z, Wu JZ, et al: Exosomes from drug-resistant breas cancer cells transmit chemoresistance by a horizontal transfer of microRNAs. PLoS One 9: e95240, 2014.

50. Vella LJ: The emerging role of exosomes in epithelial-mesenchymal-transition in cancer. Front Oncol 4: 361, 2014.

51. Nishikata $T$, Ishikawa $M$, Matsuyama $T$, Takamatsu $K$, Fukuhara T and Konishi Y: Primary culture of breast cancer: A model system for epithelial-mesenchymal transition and cancer stem cells. Anticancer Res 33: 2867-2873, 2013.

52. Qureshi R, Arora H and Rizvi MA: EMT in cervical cancer: Its role in tumour progression and response to therapy. Cancer Lett 356: 321-331, 2015.

53. Davidson B, Tropé CG and Reich R: Epithelial-mesenchymal transition in ovarian carcinoma. Front Oncol 2: 33, 2012.

54. Gou WF, Zhao Y, Lu H, Yang XF, Xiu YL, Zhao S, Liu JM, Zhu ZT, Sun HZ, Liu YP, et al: The role of RhoC in epithelialto-mesenchymal transition of ovarian carcinoma cells. BMC Cancer 14: 477, 2014.

55. Geng SQ, Alexandrou AT and Li JJ: Breast cancer stem cells: Multiple capacities in tumor metastasis. Cancer Lett 349: 1-7, 2014
56. Shimoda $\mathrm{M}$ and Khokha R: Proteolytic factors in exosomes Proteomics 13: 1624-1636, 2013.

57. Tauro BJ, Mathias RA, Greening DW, Gopal SK, Ji H, Kapp EA, Coleman BM, Hill AF, Kusebauch U, Hallows JL, et al: Oncogenic H-ras reprograms Madin-Darby canine kidney (MDCK) cell-derived exosomal proteins following epithelialmesenchymal transition. Mol Cell Proteomics 12: 2148-2159, 2013.

58. Webber J, Steadman R, Mason MD, Tabi Z and Clayton A: Cancer exosomes trigger fibroblast to myofibroblast differentiation. Cancer Res 70: 9621-9630, 2010.

59. Borges FT, Melo SA, Özdemir BC, Kato N, Revuelta I, Miller CA, Gattone VH II, LeBleu VS and Kalluri R: TGF- $\beta 1-$ containing exosomes from injured epithelial cells activate fibroblasts to initiate tissue regenerative responses and fibrosis. J Am Soc Nephrol 24: 385-392, 2013.

60. Luga V, Zhang L, Viloria-Petit AM, Ogunjimi AA, Inanlou MR, Chiu E, Buchanan M, Hosein AN, Basik M and Wrana JL: Exosomes mediate stromal mobilization of autocrine Wnt-PCP signaling in breast cancer cell migration. Cell 151: 1542-1556, 2012.

61. Da Forno PD, Pringle JH, Hutchinson P, Osborn J, Huang Q, Potter L, Hancox RA, Fletcher A and Saldanha GS: WNT5A expression increases during melanoma progression and correlates with outcome. Clin Cancer Res 14: 5825-5832, 2008.

62. Ekström EJ, Bergenfelz C, von Bülow V, Serifler F, Carlemalm E, Jönsson $\mathrm{G}$, Andersson T and Leandersson K: WNT5A induces release of exosomes containing pro-angiogenic and immunosuppressive factors from malignant melanoma cells. Mol Cancer 13: 88, 2014

63. McCready J, Sims JD, Chan D and Jay DG: Secretion of extracellular hsp90alpha via exosomes increases cancer cell motility: A role for plasminogen activation. BMC Cancer 10: 294, 2010.

64. Hendrix A, Westbroek W, Bracke M and De Wever O: An ex(o) citing machinery for invasive tumor growth. Cancer Res 70: 9533-9537, 2010

65. Kucharzewska $P$ and Belting M: Emerging roles of extracellular vesicles in the adaptive response of tumour cells to microenvironmental stress. J Extracell Vesicles 2: 20304, 2013.

66. Grange C, Tapparo M, Collino F, Vitillo L, Damasco C, Deregibus MC, Tetta C, Bussolati B and Camussi G: Microvesicles released from human renal cancer stem cells stimulate angiogenesis and formation of lung premetastatic niche. Cancer Res 71: 5346-5356, 2011

67. Diaz-Cano SJ: Tumor heterogeneity: Mechanisms and bases for a reliable application of molecular marker design. Int J Mol Sci 13: 1951-2011, 2012

68. De Palma M and Hanahan D: The biology of personalized cancer medicine: Facing individual complexities underlying hallmark capabilities. Mol Oncol 6: 111-127, 2012.

69. Igney FH and Krammer PH: Immune escape of tumors: Apoptosis resistance and tumor counterattack. J Leukoc Biol 71: 907-920, 2002.

70. Kim R, Emi M and Tanabe K: Cancer immunoediting from immune surveillance to immune escape. Immunology 121: $1-14,2007$.

71. Whiteside TL, Mandapathil M, Szczepanski M and Szajnik M: Mechanisms of tumor escape from the immune system: Adenosine-producing Treg, exosomes and tumor-associated TLRs. Bull Cancer 98: E25-E31, 2011.

72. Mandapathil M, Lang S, Gorelik E and Whiteside TL: Isolation of functional human regulatory $\mathrm{T}$ cells (Treg) from the peripheral blood based on the CD39 expression. J Immunol Methods 346: 55-63, 2009.

73. Mandapathil M, Hilldorfer B, Szczepanski MJ, Czystowska M Szajnik M, Ren J, Lang S, Jackson EK, Gorelik E and Whiteside TL: Generation and accumulation of immunosuppressive adenosine by human $\mathrm{CD} 4{ }^{+} \mathrm{CD} 25^{\text {high }} \mathrm{FOXP} 3^{+}$regulatory T cells. J Biol Chem 285: 7176-7186, 2010.

74. Clayton A, Al-Taei S, Webber J, Mason MD and Tabi Z: Cancer exosomes express CD39 and CD73, which suppress T cells through adenosine production. J Immunol 187: 676-683, 2011.

75. Pardali K and Moustakas A: Actions of TGF-beta as tumor suppressor and pro-metastatic factor in human cancer. Biochim Biophys Acta 1775: 21-62, 2007.

76. Szczepanski MJ, Szajnik M, Welsh A, Whiteside TL and Boyiadzis M: Blast-derived microvesicles in sera from patients with acute myeloid leukemia suppress natural killer cell function via membrane-associated transforming growth factorbeta1. Haematologica 96: 1302-1309, 2011. 
77. Mincheva-Nilsson L and Baranov V: Cancer exosomes and NKG2D receptor-ligand interactions: Impairing NKG2Dmediated cytotoxicity and anti-tumour immune surveillance. Semin Cancer Biol 28: 24-30, 2014.

78. Szajnik M, Czystowska M, Szczepanski MJ, Mandapathil M and Whiteside TL: Tumor-derived microvesicles induce, expand and up-regulate biological activities of human regulatory T cells (Treg). PLoS One 5: e11469, 2010.

79. Whiteside TL: What are regulatory T cells (Treg) regulating in cancer and why? Semin Cancer Biol 22: 327-334, 2012.

80. Stenqvist AC, Nagaeva O, Baranov V and Mincheva-Nilsson L: Exosomes secreted by human placenta carry functional Fas ligand and TRAIL molecules and convey apoptosis in activated immune cells, suggesting exosome-mediated immune privilege of the fetus. J Immunol 191: 5515-5523, 2013.
81. Abusamra AJ, Zhong Z, Zheng X, Li M, Ichim TE, Chin JL and Min WP: Tumor exosomes expressing Fas ligand mediate CD8 ${ }^{+}$ T-cell apoptosis. Blood Cells Mol Dis 35: 169-173, 2005.

82. Bergmann C, Strauss L, Wieckowski E, Czystowska M, Albers A, Wang Y, Zeidler R, Lang S and Whiteside TL: Tumor-derived microvesicles in sera of patients with head and neck cancer and their role in tumor progression. Head Neck 31: 371-380, 2009. 